\title{
Gene delivery to neuroblastoma cells by poly (L-lysine)-grafted low molecular weight polyethylenimine copolymers
}

Saeedeh Askarian ${ }^{\mathrm{a}, \mathrm{c}}$, Khalil Abnous ${ }^{\mathrm{b}}$, Majid Darroudi ${ }^{\mathrm{c}}$, Reza Kazemi Oskuee ${ }^{\mathrm{a}, \mathrm{d}^{*} \text {, }}$ Mohammad Ramezani, 
Abstract: Polyethylenimine (PEI) and poly (L-lysine) (PLL) are among the most investigated non-viral gene carriers However, both polymers contain deficiencies that restricttheir applications. In the present study, we synthesized PLL-alkylPEI conjugates via 6-carbon alkyl linker and investigated their possible advantages in gene delivery. Four PLL copolymers were synthesized with different molecular weights and ratios of PEI. The physiochemical properties of synthesized conjugatessuch as size, zeta potential, DNA condensation ability, buffering capacity and cytotoxicity were investigated. Renilla luciferase assay was employed to evaluate the gene transfection efficiency of pDNA-polymer to Neuro2A cell line. DNA condensation and particle size measurements showed that new PLL-PEI conjugates could form polyplexes in nanoscale size in the range of 99-122 nm and were able to condense DNA at low concentration. While cytotoxicity reduced in some groups, the transfection efficiency increased about 2.8 and 4 fold as compared to the unmodified PEI $1.8 \mathrm{kDa}$ and 10 $\mathrm{kDa}$, respectively. The results of the present study showed that the chemical modifications of PEI with PLL could significantly improve transfection efficiency and PLP10-10\% shows the most promise as a new gene carrier.

Keywords: Cytotoxicity, Gene delivery, Nanoparticles, Non-viral vector, Poly (L-lysine), Polyethylenimine. 


\section{Introduction}

Most of the gene therapy clinical trials have been performed in cancers, inherited monogenic and cardio vascular diseases. Two main challenges in gene therapy include the lack of efficient gene delivery system or/and appropriate invivo selection guidelines [1]. Various delivery strategies and gene carriers have been employed in gene therapy studies which are categorized into viral and non-viral systems. Viral vectors have been utilized in a variety of clinical trials such as retrovirals in severe combined immuno deficiency (SCID) [2], lentivirals in Xlinked adreno leukodystrophy (X-ALD) [3] or recombinant adeno-associated virals (rAAV) in Leber's congenital amaurosis(LCA) diseases [4]. Although viral vectors exhibit high and rapid gene delivery efficiency, their applications have declined in recent years because (1) they have small capacity and are unable to carry large genes which are necessary for clinical applications, (2) they may activate proto-oncogenes due to random insertion of their genome into chromosomes [5], (3) they induce strong immune responses limite multiple injections and (4) there are difficulties in large scale production. Safety-concerns about the viral vectors have promoted the development of non-viral carriers. Although the transfection efficiencies of non-viral vectors are low in short-term delivery as compared with viral vectors, they have advantages including less infection risk, low cost of production, unlimited plasmid size and low immunogenicity [6]. Because of the flexibility in structures and designs of non-viral carriers, there have been many attempts to improve transfection efficiency and overcome their deficiencies. Liposomes and polymers are the most investigated non-viral vectors [7]. Enormous libraries of polymeric nanoparticles have been examined for gene delivery such as polyethylenimine (PEI) [8], dendritic poly(amidoamine) (PAMAM) [9], poly( $\beta$-amino ester) [10], polypropylenimine (PPI) [11] and poly(L-lysine) (PLL) [12]. Cationic polymers especially polyethylenimineand poly(L-lysine) are popular because they are positively charged and contain intrinsic affinity for negatively charged oligonucleotides and cell surfaces [13]. Both polymers can effectively condense pDNA and protect it from enzymatic degradation. PEI reveals excellent buffering capacity which canfacilitate rupture lysosomes and release their cargo into cytoplasm, whereas PLL exhibits weak transfection efficiency due to slow release of PLL IDNA polyplexes from endosomes [14]. Unlike PLL, PEI is not biodegradable and its cytotoxicity depends on its molecular weight and the type of cell tested.

In order to increase the transfection efficiency of PLL and to reduce the cytotoxicity of PEI, we synthesized copolymers by conjugating low molecular weight PEI (1.8 and $10 \mathrm{kDa})$ to a PLL core to take advantage of the properties of both PLL and PEI.

\section{Materials and methods}

\subsection{Materials}

Branched polyethylenimine with an average molecular weight of 10,000 Da (PEI $10 \mathrm{kDa}$ ) and $1800 \mathrm{Da}$ (PEI 1.8 $\mathrm{kDa}$ ), poly (L-lysine) (PLL; Mw $\sim 15-30 \mathrm{kDa}$ ) were purchased from Polyscience, Inc. (Warrington,PA, USA). The pRL-CMV and pEGFPN1 plasmids were obtained from Promega (Madison, WI, USA). Fetal bovine serum (FBS) and Roswell Park Memorial Institute medium (RPMI) were purchased from Gibco (Gaithersburg, MD). Methylthiazoletetrazolium 3-(4,5-dimethylthiazol-2-yl)-2,5-diphenyl tetrazolium bromide (MTT; tissue culture grade), 6-bromohexanoic acid, 1-ethyl-3-(3-dimethylaminopropyl) carbodiimide hydrochloride (EDC) were purchased from Sigma-Aldrich (Munich, Germany). Ethidium bromide was purchased from Cinnagen (Tehran,Iran). Spectra/Por dialysis membranes (Spectrum Laboratories, Houston, TX, USA) were utilized for dialyses.

\subsection{Synthesis of nanoparticles}

The branched polyethylenimine $(1.8 \mathrm{kDa}$ and $10 \mathrm{kDa})$ were dissolved in double distilled water $\left(\mathrm{ddH}_{2} \mathrm{O}\right)$, then 14 $\mathrm{mg}$ (excess amount) of 1-ethyl-3-(3-dimethylaminopropyl) carbodiimide (EDC) was separately dissolved in $\mathrm{ddH}_{2} \mathrm{O}$ and added to PEI while the mixture was stirred vigorously. Poly (L-lysine) was dissolved in dimethylsulphoxide (DMSO) and 6-bromohexanoic acid was added dropwise over a period of $2 \mathrm{~h}$ to a vigorously stirred solution. The reaction was allowed to proceed at room temperature for another $24 \mathrm{~h}$ and then diluted with 
$\mathrm{ddH}_{2} \mathrm{O}$. The resulted solutions were dialyzed using 8000 cut-off membrane (Spectra/Pormembrane) against 150 $\mathrm{mM} \mathrm{NaCl}$ for 1 day and then $\mathrm{ddH}_{2} \mathrm{O}$ for 2 days to remove unreacted alkylcarboxylates. The PLLalkylcarboxylate solution was added dropwise over a period of $2 \mathrm{~h}$ to vigorously stirred PEI solution and the reaction was proceeded for overnight. For purification, the mixture containing PLL-PEI conjugates was transferred to a dialysis membrane with 10000 and 25000cut-off for $1.8 \mathrm{kDa}$ and $10 \mathrm{kDa}$ PEI solutions, respectively (Spectra/Por membrane). Dialysis was performed against $150 \mathrm{mM} \mathrm{NaCl}$ saline solution for 1 day and then $\mathrm{ddH}_{2} \mathrm{O}$ for 2 days to remove unreacted polymers. After the dialysis, the remained solution was lyophilized to yield a dry powder. Stock solutions $(1 \mathrm{mg} / \mathrm{ml})$ were prepared for further application.

\subsection{Size distribution and zeta-potential measurements}

The particle size and surface charge were measured for vector/pDNA polyplexes by dynamic light scattering (DLS) and laser dopplervelocimeter (LDV) using a Malvern Zetasizer Nano ZS (Malvern Instruments, Malvern, UK). The desired amount of conjugated polymers was diluted in $150 \mu$ l filtered doubly-distilled water in physiological $\mathrm{pH}(\mathrm{pH}=7.4)$ and mixed with $150 \mu \mathrm{l}$ pNA solution (containing desired amount of plasmid) and left for $20 \mathrm{~min}$ at room temperature to form the polyplexes. Then, $700 \mu \mathrm{l}$ water was added and the solution was utilized for size and zeta potential measurements. The final polymers concentration was at cationic/plasmid $(\mathrm{w} / \mathrm{w})$ ratio at $\mathrm{C} / \mathrm{P}=4$. Values were presented as mean $\pm \mathrm{SD}$ for three measurements.

\subsection{Determination of buffering capacity}

Synthesized conjugates with concentration of $0.4 \mathrm{mg} / \mathrm{ml}$ were dissolved in $1 \mathrm{ml}$ of $\mathrm{ddH}_{2} \mathrm{O}$ and the $\mathrm{pH}$ was adjusted to 12 using $1 \mathrm{M} \mathrm{NaOH}$. The $\mathrm{pH}$ was measured using a $\mathrm{pH}$ meter (Mettler Todelo, Greifensee, Switzerland) at room temperature (about $25^{\circ} \mathrm{C}$ ) after addition of each five microliter of $0.1 \mathrm{M} \mathrm{HCl} \mathrm{until} \mathrm{pH} \mathrm{of}$ 2.5 was obtained. The buffering capacity of polymers was estimated from the slope of $\mathrm{pH}$ plot versus the amount of $\mathrm{HCl}$ added.

\subsection{Ethidium bromide (EtBr) exclusion assay}

DNA condensation ability of nanopolymerswas evaluated by ethidium bromide (EtBr) exclusion assay. The fluorescence intensity of $400 \mathrm{ng} / \mathrm{ml}$ ethidium bromide solutionwas measured at $\lambda_{\text {ex }} 510 \mathrm{~nm}$ and $\lambda_{\text {em }} 590 \mathrm{~nm}$ using a Jasco FP-6200 spectrofluorimeter (Jasco Global, FP-6200, Japan). Upon addition of pDNA(10 $\mu \mathrm{g} / \mathrm{ml})$ to ethidium bromide solution, the fluorescence intensity increased which was regarded as $100 \%$. The decrease of EtBr fluorescence intensity was measured following addition of pre-determined amounts $(2.5 \mu 1 \mathrm{of} 1 \mathrm{mg} / \mathrm{ml}$ solution) of PLL-PEI conjugates to the pDNA-ethidium bromide solution. The experiments were performed in triplicate and results were reported by plotting the relative fluorescence intensity (\%) against the carrier/plasmid ratio $(\mathrm{w} / \mathrm{w})$.

\subsection{Measurement of primary amine content}

The primary amines of PLL after grafting with 6-bromohexanoic acid was determined by 2,4,6trinitrobenzenesulfonic acid (TNBS) assay using the standard method [15]. The difference in the amounts of primary amines on unmodified PLL and conjugated PLL, revealed the degrees of alkylcarboxylate grafting to PEI.

\subsection{Preparation of plasmid DNA}

The pRL-CMV plasmid (Promega, Madison, WI) coding Renilla luciferase reporter gene was transformed into Escherichia coli bacterial strain DH5 $\alpha$. The transformed bacteria was cultured in selective Luria-Bertani (LB) medium and plasmid was extracted from the cell pellets using Qiagen endotoxin-free Mega Plasmid kit (Qiagen, Hilden, Germany) according to the manufacturer's instructions. The concentration and purity of the plasmid were estimated using the A260 and A260/A280, respectively, using a UV-Visible spectrophotometer (Pharmaspec, UV-1700; Specto, Shimadzu, Japan). The highest purity and mostly supercoiled plasmids were selected after agarose gel electrophoresis.

\subsection{Cell culture and cytotoxicity assay}


Neuro2A (murine neuroblastoma) cells (ATCC CCL-131) were cultured in DMEM (1 g/l glucose, $2 \mathrm{mM}$ glutamine) supplemented with $10 \% \mathrm{FBS}, 100 \mu \mathrm{g} / \mathrm{ml}$ streptomycin and $100 \mathrm{U} / \mathrm{ml}$ penicillin. All cells were incubated at $37^{\circ} \mathrm{C}$ in a humidified $5 \% \mathrm{CO}_{2}$ atmosphere. Cells were seeded in 96 -well plates at a density of $1 \times$ $10^{4}$ cells/well and cultured for $24 \mathrm{~h}$ before transfection and toxicity assay. Polyplexes containing $2 \mu \mathrm{g}$ plasmid/well were prepared at C/P ratios of 2:1, 4;1 and 6:1 (w/w). Polyplexes were mixed in aqueous solution $(20 \mu \mathrm{l})$ without serum and incubated for $30 \mathrm{~min}$ at room temperature then added to each well. After $4 \mathrm{~h}$, the medium was removed and replaced with $100 \mu \mathrm{l}$ fresh complete growth media and incubated for additional $24 \mathrm{~h}$. The metabolic activity assay (MTT) was performed by adding $20 \mu \mathrm{l}$ of MTT solution $(5 \mathrm{mg} / \mathrm{ml})$ to each well and incubating the plates for $2 \mathrm{~h}$ at $37^{\circ} \mathrm{C}$. The absorbance was measured at $550 \mathrm{~nm}$ (reference wavelength 630 $\mathrm{nm}$ ) using a microplate reader (ELx800; BioTekInc, Winooski, VT, USA). The relative metabolic activities were expressed as absorbance percentage of treated cells related to control cells (Cell viability $=A_{\text {treated }} / A_{\text {control }}$ $\times 100$ ) and presented as the mean $\pm \mathrm{SD}$ of triplicate.

\subsection{Transfection procedure}

Transfection experiments were performed in similar conditions with the same amount of polyplexes used for cytotoxicity experiment. The polyplexeswere prepared in different C/P ranging from 2:1 to 6:1 and were added to cells. The medium was removed after $4 \mathrm{~h}$ and replaced with $100 \mu \mathrm{l}$ of serum supplemented DMEM. The cells were harvested $24 \mathrm{~h}$ post-transfection and resuspended in lysis buffer. The luciferase activity was measured using PromegaRenilla Luciferase assay kit and a luminometer (Berthold Detection Systems, Pforzheim, Germany). The results were presented as relative light units (RLU) per number of seeded cells, mean $\pm S D, n=3$. Branched $25 \mathrm{kDa}$ PEI in C/P 0.8 was used as a positive control for transfection experiments.

\subsection{Statistical analysis}

Results were analyzed using one-way analysis of variance (ANOVA) followed by Tukey's multiple comparison test. $\mathrm{p} \leq 0.05$ was considered as statistically significant.

\section{Results and discussion}

\subsection{Preparation and charactrizationof polyplexes}

In the present study, $1.8 \mathrm{kDa}$ and $10 \mathrm{kDa}$ PEIs were grafted to PLL via an alkylcarboxylate (6-bromohexanoic acid) as the linker. Thus, alkylcarboxylate moiety was reacted with $10 \%$ and $50 \%$ of the PLL primary amine groups. The TNBS assay was performed to estimate the degree of PLL primary amine substitutions by alkylcarboxylate groups. As shown in Table 1, the percentages of substitutions were $8.2 \%$ and $35.8 \%$ for $10 \%$ and $50 \%$ feed mol ratio, respectively. In the next step, solution of alkycarboxylate derivative of PLL was added dropwise to the activated PEI solution, to yield PLL-PEI conjugates (Fig. 1). New PLL-PEI conjugates with structure of PLL-hexanoate-10\%-PEI1.8 kDa and PLL-hexanoate-50\%-PEI $1.8 \mathrm{kDa}$ were abbreviated as PLP1.8-10\% and PLP1.8-50\%, respectively. Similarly, conjugates having PEI $10 \mathrm{kDa}$ were abbreviated as PLP10-10\% and PLP10-50\%, respectively.

The effective diameters of polyplexes had been reported in the range of 30 to $500 \mathrm{~nm}$ [16]. The results showed that the new PLL-PEI conjugates were able to form nanoparticles in the range of 99-122 nm. However, their zeta potentials were lower than unmodified PEIs, the zeta potentials of these polyplexes were between 15.2 and $23.5 \mathrm{mV}$ which increased with increasing the feed mole percentages of coupled PEI.

\section{Table1}

The particle size and surface charge of nanoplexes. Data are expressed as mean values \pm SD. PLL-hexanoic10\%-PEI and PLL-hexanoic-50\%-PEI abbreviated to PLPX10\% and PLPX50\%, respectively. X represents the PEI molecular weight 1.8 or 10 for PEI 1.8kDa and PEI 10kDa. 


\begin{tabular}{ccc}
\hline NPs & $\begin{array}{c}\text { Size of DNA/polymer } \\
\text { complex } \\
(\mathbf{n m} \pm \text { SD) }\end{array}$ & $\begin{array}{c}\text { Zeta potential of } \\
\text { DNA/polymer complex } \\
(\mathbf{m V} \pm \text { SD) }\end{array}$ \\
\hline PEI 1.8kDa & $61.3 \pm 4.0$ & $23 \pm 2$ \\
PLP1.8-10\% & $122.3 \pm 3.4$ & $15.2 \pm 0.9$ \\
PLP1.8-50\% & $109.3 \pm 9.4$ & $20.6 \pm 2.8$ \\
& & \\
PEI 10kDa & $87.6 \pm 2.5$ & $24.2 \pm 3.7$ \\
PLP10-10\% & $101.8 \pm 15.7$ & $21.2 \pm 2.6$ \\
PLP10-50\% & $99 \pm 7$ & $23.5 \pm 2$ \\
PLL & $73.6 \pm 1.06$ & $4.9 \pm 2$ \\
\hline
\end{tabular}

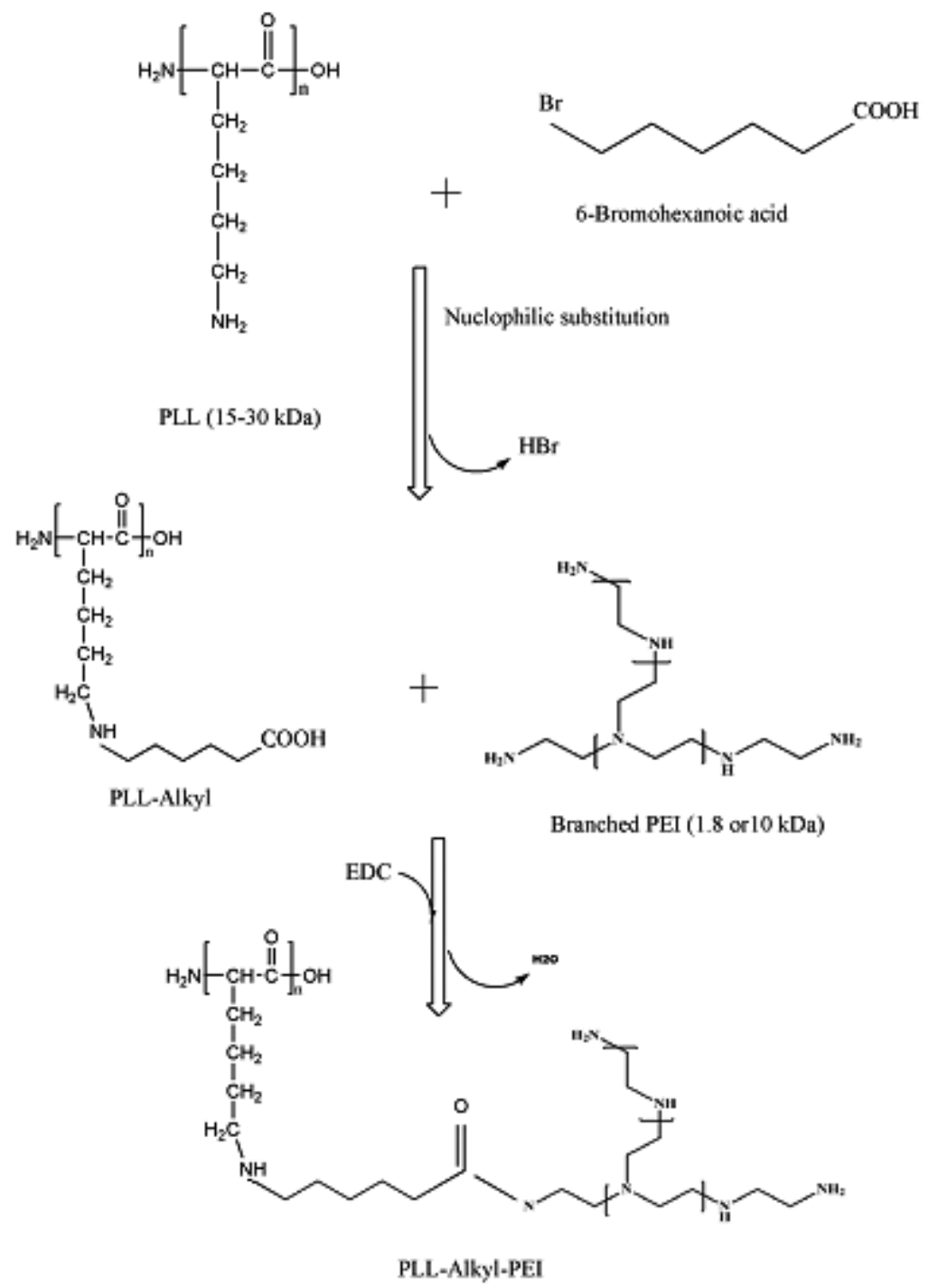

Fig. 1. Synthesis of alkyl carboxylate PLL-grafted PEI derivatives.

\subsection{DNA condensation and buffering capacity of polymers}

The ability of PLL-PEI conjugatesto condense pDNA and to form polyplexes is critical for efficient gene delivery into cells. The polyplex formation was evaluated by ethidium bromide (EtBr) exclusion assay. Ethidium bromide is an intercalating dye and could associate with free dsDNA. Fluorescence intensity decreases as polymer condense DNA and excludesEtBrdsDNA. All conjugates were able to condense pRL-CMV plasmid 
DNA at $\mathrm{C} / \mathrm{P}$ ratiosmore than 2 whereas PLL showed a weak positive charge density and could not tightly bind to DNA andtherefore, condensed pDNAat C/P more than 4 (Fig.2). Appropriate DNA condensation ability is one of the necessary features of polymers for gene delivery. Because of few positive charge of PLL, it condensed DNA at higher $\mathrm{C} / \mathrm{P}$ ratio, whereas all modified polymers were able to condense pDNA in the presence of low polymer concentrations $(\mathrm{C} / \mathrm{P}<1)$. Sizes of prepared polyplexes were less than $200 \mathrm{~nm}$ which were suitable for being taken up by the cells via clathrin-mediated endocytosis [17].
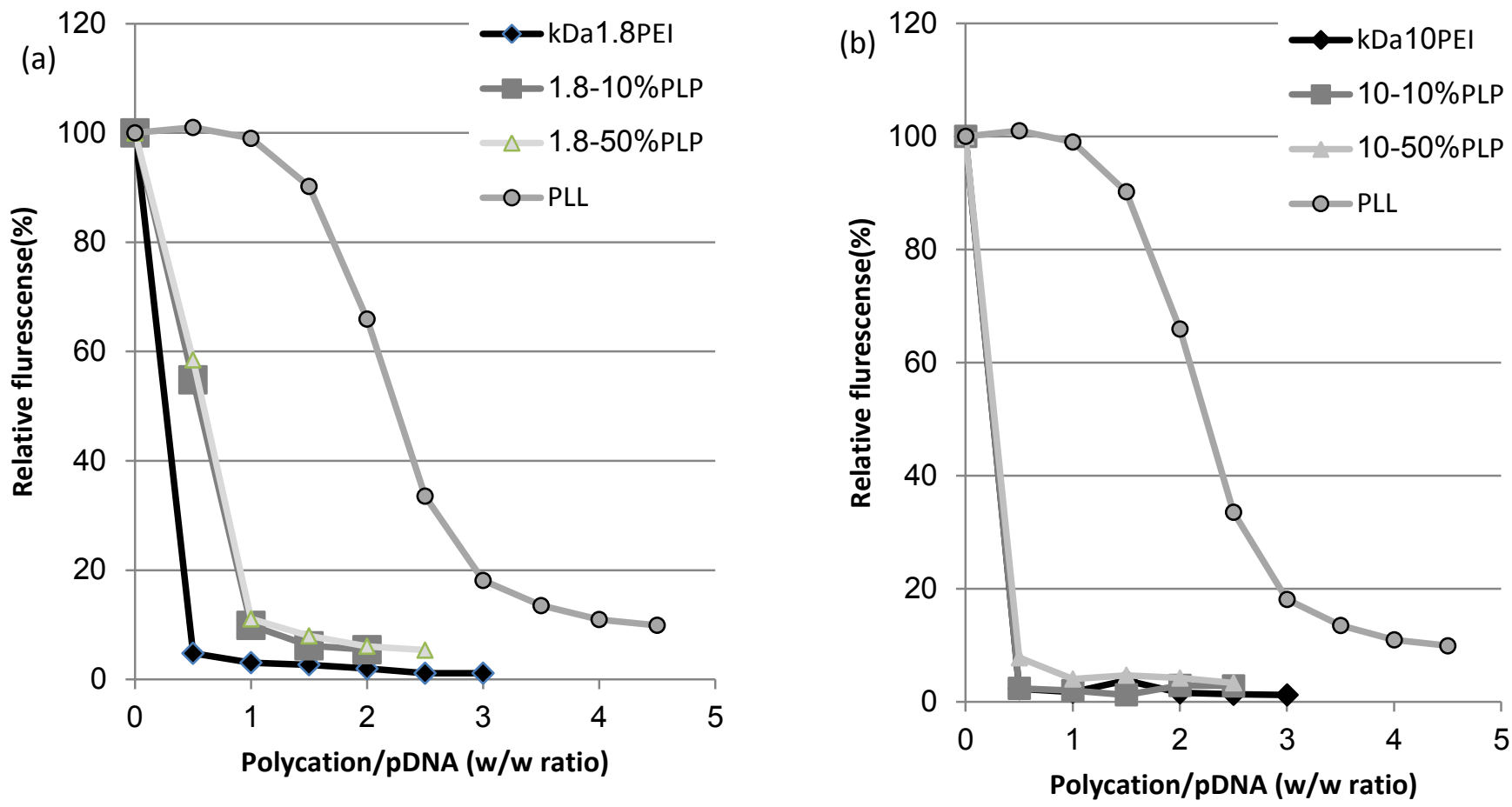

Fig.2. Condensation profile of pDNA, measured by ethidium bromide (EtBr) exclusion assay in HBG buffer. PLL-PEI conjugates with (a) $1.8 \mathrm{kDa}$ and (b) $10 \mathrm{kDa}$ PEI.

The PEI can easily induce proton sponge effect which is the main mechanism leading to osmotic swelling and rupturing, due to excellent buffering capacity over the $\mathrm{pH}$ range (5.5-7) of endosome [18, 19]. However, PLL exhibits weaker buffering capacity at this $\mathrm{pH}$ range which is attributed to the lack of secondary and tertiary amines [20]. Therefore it is expected that PLL alone could not facilitate endosomal release of polyplexes through osmotic burst mechanism. According to the results, all synthesized conjugates exhibited buffering capacity over the endosomal $\mathrm{pH}$ ranges similar to unmodified PEI $1.8 \mathrm{kDa}$ and PEI $10 \mathrm{kDa}$, whereas the PLL showed weak buffering capacity at this critical $\mathrm{pH}$ range. These results confirmed the weak buffering capacity of PLL and indicated that PLL-PEI conjugates had the had the appropriate buffering capacity at the endosomal $\mathrm{pH}$ range. 
(a) 14

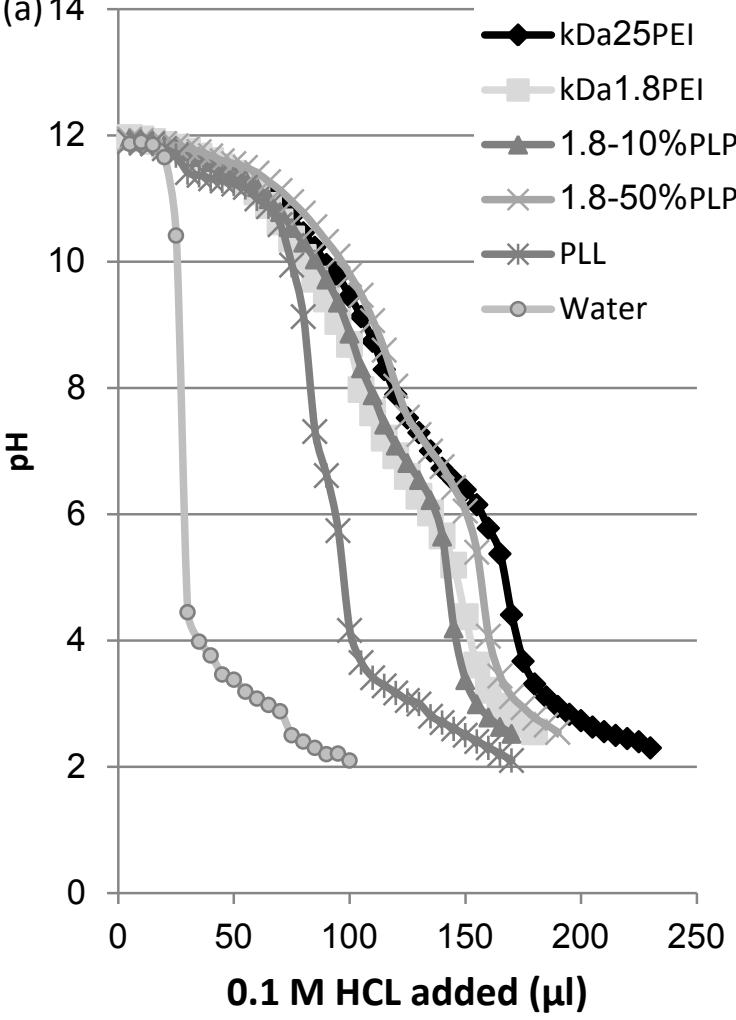

(b) 14
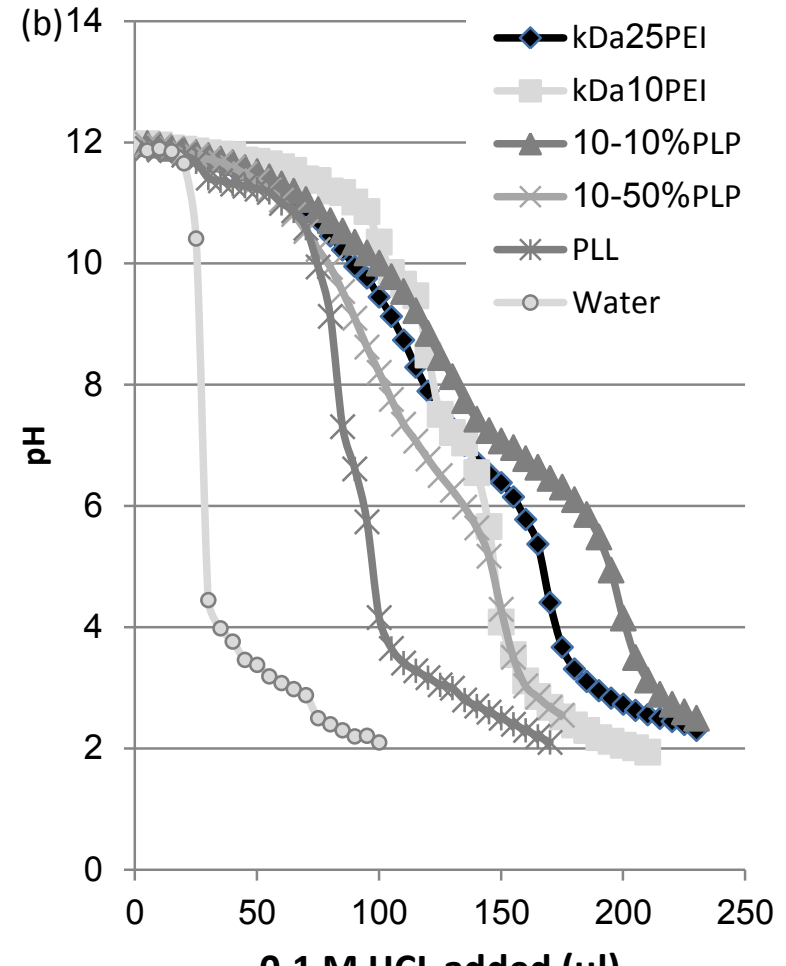

$0.1 \mathrm{M} \mathrm{HCL}$ added $(\mu \mathrm{l})$

Fig.3. The titration curves of PLL-PEI conjugates. At first, pHsof all samples were adjusted to 12 with $\mathrm{NaOH}$ (1M) and then titration curves were plotted by subsequent addition of $5 \mu \mathrm{l} 0.1 \mathrm{M} \mathrm{HCl}$ until the pH reached 2 . Deionized water and PEI $25 \mathrm{kDa}$ were included as the controls.

\subsection{Cytotoxicity and transfection efficiency of polyplexes}

Although both polyethylenimine (PEI) and poly (L-lysine) (PLL) are the most investigated polymers as nonviral gene carriers, but there are drawbacks in their applications. PLL reveals poor transfection efficiency and low stability [14], while, PEI with its excellent "proton sponge" effect is not biocompatible and shows cytotoxicity [21]. Many attempts have been made to modify PLL structure and make a suitable gene delivery system such as pullulan-g-poly(L-lysine) [22] and PLL-PEG-FOL conjugate [23].

Contrary to PEIs, PLL is a biodegradable molecule and seems to be more suitable for in vivo applications. There are different PEIs with molecular weight ranging from few hundred to $1500 \mathrm{kDa}$ [24] and cytotoxicity of PEIs depend on their molecular weight (MW), structure and the cell type used [21, 25]. It was reported that in vitro transfection efficiency increased with higher MW branched PEIs, ranging from 1.8 to $70 \mathrm{kDa}$ [26]. In contrast, another study found that invitro transfection activity decreased as MW increased from 1.8 to $70 \mathrm{kDa}$ [27]. In our study, we synthesized PLL-PEI conjugates to take advantages of both PLL and PEI properties. Thus, $1.8 \mathrm{kDa}$ and $10 \mathrm{kDa}$ PEIs were added to primary amines of PLL via hexanoate as the linker.

The cytotoxicity of polyplexes was determined using MTT assay at C/P ratios of 2:1, 4:1 and 6:1 in Neuro2a cells. The cytotoxicity of the produced copolymers was similar to that of unmodified PEI. The cell viabilities after transfection with low molecular weight PEI derivatives were not significantly different from those of PEI $1.8 \mathrm{kDa}$ itself (Fig. 4c). The cell viability of PLP10-10\% enhanced at $\mathrm{C} / \mathrm{P}=2$ compared to unmodified PEI 10 $\mathrm{kDa}$. Cytotoxicity increased at higher $\mathrm{C} / \mathrm{P}$ ratios, though at lower grafting conjugate (i.e.PLP10-10\%), it was not significantly different from those unmodified observed with PEI $10 \mathrm{kDa}$ (Fig. 4d). However, PLP10-50\% showed cytotoxicity at higher $\mathrm{C} / \mathrm{P}$ ratios of 4 6. As expected, PLL showed no cytotoxicity at all $\mathrm{C} / \mathrm{P}$ ratios tested. 
The gene transfection efficiency of PLL-PEI conjugates was evaluated in Nero2A cells using Renilla luciferase assay at C/P ratios of 2:1, 4:1 and 6:1. The results were compared to those of unmodified PEIs (1.8 $\mathrm{kDa}$ and 10 $\mathrm{kDa}$ ) and PLL. In overall, the results showed the transfection efficiency in PLPX-10\% series were enhanced regardless of the molecular weight of used PEI. Higher degree of PEI substitution (PLPX-50\%) resulted in lower or no significant changes in gene transferring ability to cells. It was assumed that increase in grafting percentage of PEIs in the PLL-PEI copolymers had an impact on the cytotoxicity of polyplexes thus reducing the transfection activity. Although cell viability showed no differences in PLP1.8-10\% or PLP1.8-50\% treatments, but PLP10-50\% displayed higher cytotoxicity even more than that of unmodified PEI 10kDa at higher $\mathrm{C} / \mathrm{P}$ ratios which might resulted in lower transfection efficiency.

It was observed that both PLP1.8-10\% and PLP10-10\% were able to transfer plasmid DNA more efficiently than their unmodified PEIs, while PLL itself showed the lowest transfection efficiency at all tested C/P ratios. PLP1.8-10\% enhanced gene transfection ability up to 2 and 2.8 folds at C/P 4 and 6 , respectively. Transfection efficiency of PLP10-10\% increased about 4 and 3 folds at C/P 2 and 4, respectively (Fig. 4a-b).

The cytotoxicity of polyethylenimine is the most limiting aspect for utilizing them as a gene carrier. Different modification of PEI were reported in attempts to reduce the cytotoxicity of PEI, such as PEGylation [28] or acylation [29]. According to our results, PEI $10 \mathrm{kDa}$ showed moderate cytotoxicity at low C/P, but cell viability reduced as the amount of polymers increased. Former studies also revealed that PEI $1.8 \mathrm{kDa}$ was less cytotoxic and could be eliminated from body through kidneys.[30]. It was reported that low molecular weight PEIs were less toxic but inefficient for gene delivery purposes [21]. Although several PEI $1.8 \mathrm{kDa}$ molecules existed in PLP1.8-10\% structure but its cytotoxicity did not increase, while transfection efficiency increased about 2.8 fold as compared to unmodified PEI $1.8 \mathrm{kDa}$. Interestingly, cell viability increased at low C/P ratio in PEI $10 \mathrm{kDa}-$ based polyplexes. Decrease in cytotoxicity may have resulted in enhancement of PLP10-10\% transfection efficiency by about 4 fold ascompared to unmodified PEI 10kDa. These results indicated that our hypothesis for achieving more efficient and less toxic non-viral vector was somewhat successful. Although the branched PEI $25 \mathrm{kDa}$ with high cationic charge induced cytotoxicity due to that strong attachment and disruption of cell membrane, but is still considered as golden standard for gene delivery studies [31].

Direct conjugation of PLL to linear PEI [32] was prepared and tested for gene delivery where amino groups of PLL were partially grafted with low molecular weight linear PEI. The results showed reduction in cytotoxicity and increase in transfection efficiency as compared to each of the unmodified polymers. Beside, conjugation of biodegradable polycations such as polycarbonates and polyaspartamide to branched PEIs with low molecular weights could reduce the safety concern of gene transfection [33, 34]. In a similar study, PLL was introduced into branched PEI $25 \mathrm{kDa}$ by ring-opening polymerization (ROP) of $\varepsilon$-benzyloxycarbonyl-L-lysine $\mathrm{N}$ carboxyanhydride [35]. In this study, different feed ratios of Lys(Z)-NCA were added to PEI which resulted in new polymers for gene delivery to induce apoptosis. 


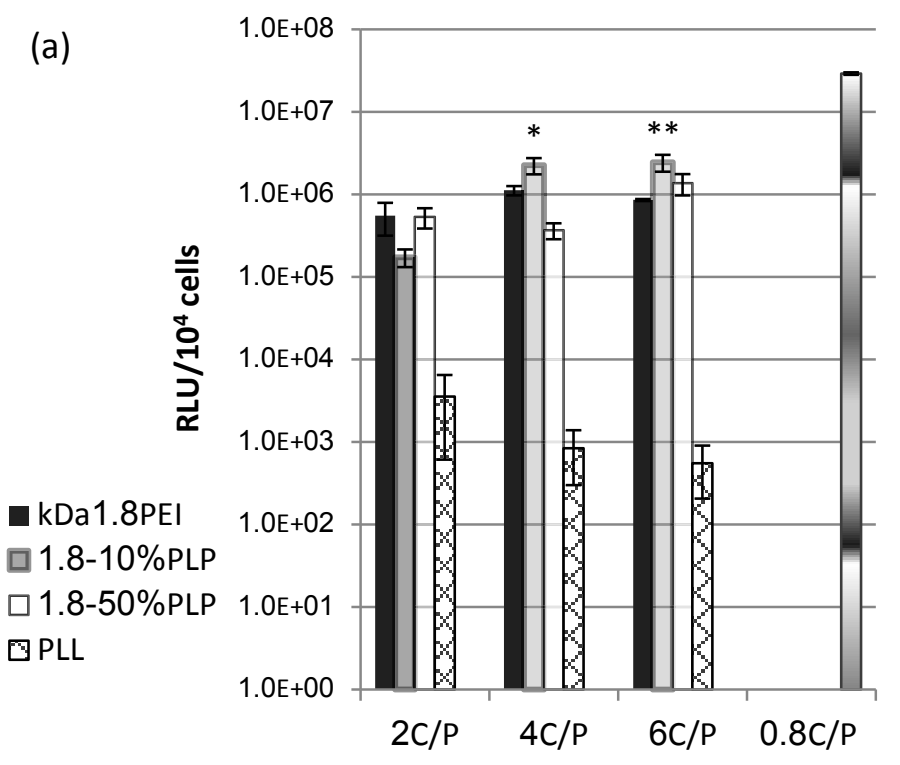

(b)

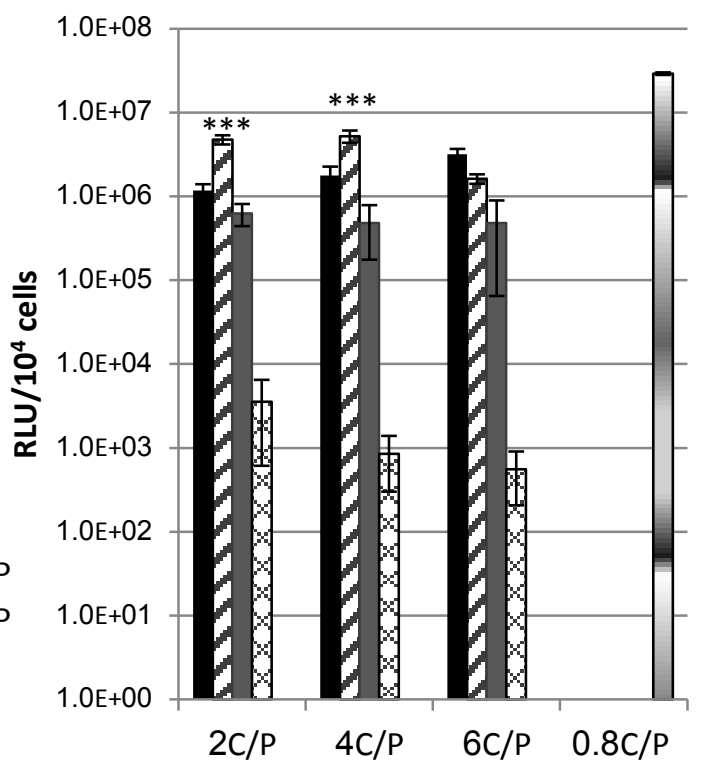

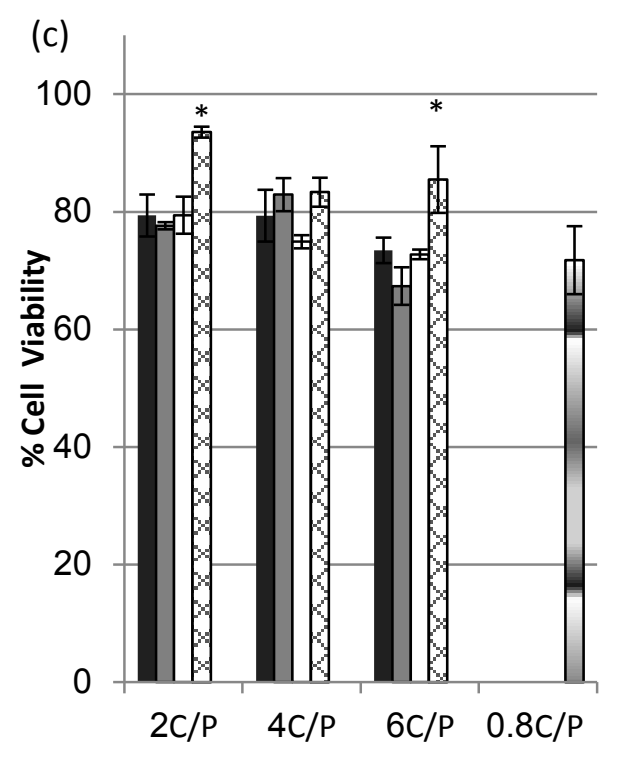

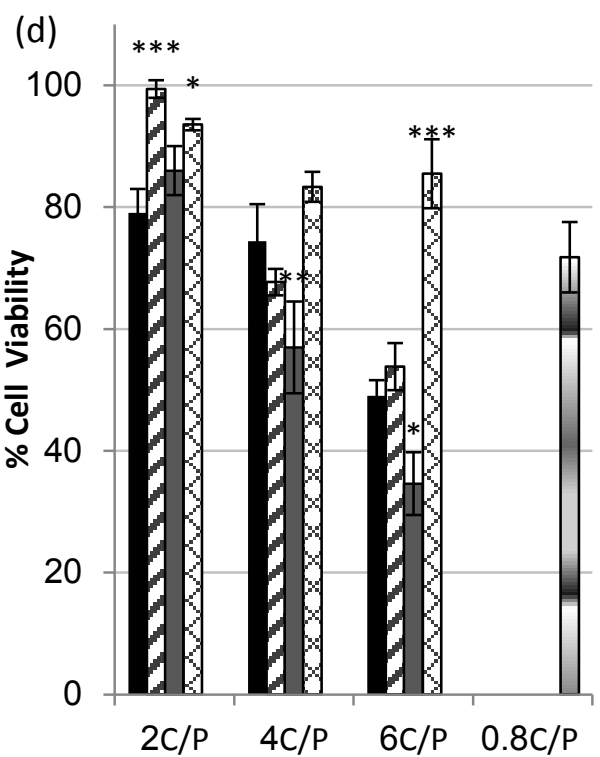

Fig.4. Transfection efficiency (a-b) and cell viability (c-d) of modified polymers at different polycation/plasmid ratios (w/w) of 2:1, 4:1 and 6:1. Neuro2A cells were transfected with polyplexes of PLP1.8 (a, c), PLP10 series $(\mathbf{b}, \mathbf{d})$. Polyplexes with PLL, PEI $1.8 \mathrm{kDa}$ and $10 \mathrm{kDa}$ utilized as controls at the indicated $\mathrm{C} / \mathrm{P}$ ratios, as well as the polyplexes prepared with $25 \mathrm{kDa} \mathrm{PEI}$ in $\mathrm{C} / \mathrm{P} 0.8$. All experiments were performed in triplicate and data were presented as mean \pm SD. ${ }^{*} \mathrm{p}<0.05,{ }^{* *} \mathrm{p}<0.01$ and ${ }^{* * *} \mathrm{p}<0.001$ synthesized polymers as compared with unmodified PEIs.

\section{Conclusion}

In the present study, PLL-PEI conjugates with different molecular weight PEIs (1.8 $\mathrm{kDa}$ and $10 \mathrm{kDa})$ were synthesized. The physicochemical properties such as size, zeta potential and DNA condensation capability showed that these conjugates were suitable for gene delivery.The transfected efficiency of PLP10-10\% was nearly four folds higher than that of PEI $10 \mathrm{kDa}$. The cell viability and transfection results exhibited that PLP1.8-10\% and PLP10-10\% were better gene transfer carriers for gene delivery as compared to unmodified PEI. Our results suggested the PLL-PEI conjugates as appropriate carriers for gene delivery purposes. 


\section{Conflict of interest}

The authors confirm that this article content has no conflict of interest.

\section{Acknowledgments}

This work was founded by the Mashhad University of Medical Sciences, Mashhad, Iran. Financial support from Iran National Science Foundation (INSF) and Iran Nanotechnology Initiative is acknowledged. We would like to gratefully acknowledge Dr. Sara Amel Farzad in Avicenna Research Institute for her assistance with laboratory experiments. This work was a part of Saeedeh Askarian Ph.D. thesis.

\section{References}

[1] Ginn SL, Alexander IE, Edelstein ML, Abedi MR, Wixon J. Gene therapy clinical trials worldwide to 2012 an update. J Gene Med, 2013;15:65-77.

[2] Herzog RW. Gene therapy for SCID-X1: round 2. Mol Ther 2010;18:1891.

[3] Cartier N, Aubourg P. Hematopoietic stem cell transplantation and hematopoietic stem cell gene therapy in X-linked adrenoleukodystrophy. Brain Pathology 2010;20:857-62.

[4] Simonelli F, Maguire AM, Testa F, Pierce EA, Mingozzi F, Bennicelli JL, et al. Gene therapy for Leber's congenital amaurosis is safe and effective through 1.5 years after vector administration. Mol Ther 2010;18:643-50.

[5] Hacein-Bey-Abina S, Von Kalle C, Schmidt M, McCormack MP, Wulffraat N, Leboulch P, et al. LMO2associated clonal $\mathrm{T}$ cell proliferation in two patients after gene therapy for SCID-X1. Science 2003;302:4159.

[6] Vercauteren D, Rejman J, Martens TF, Demeester J, De Smedt SC, Braeckmans K. On the cellular processing of non-viral nanomedicines for nucleic acid delivery: mechanisms and methods. J Control Release 2012;161:566-81.

[7] Ewe A, Schaper A, Barnert S, Schubert R, Temme A, Bakowsky U, et al. Storage stability of optimal liposome-polyethylenimine complexes (lipopolyplexes) for DNA or siRNA delivery. Acta Biomater 2014;10:2663-73.

[8] Tripathi SK, Gupta N, Mahato M, Gupta KC, Kumar P. Selective blocking of primary amines in branched polyethylenimine with biocompatible ligand alleviates cytotoxicity and augments gene delivery efficacy in mammalian cells. Colloids Surf B Biointerfaces 2014;115:79-85.

[9] Shcharbin D, Shakhbazau A, Bryszewska M. Poly(amidoamine) dendrimer complexes as a platform for gene delivery. Expert Opin Drug Deliv 2013;10:1687-98.

[10] Segovia N, Dosta P, Cascante A, Ramos V, Borrós S. Oligopeptide-terminated poly( $\beta$-amino ester)s for highly efficient gene delivery and intracellular localization. Acta Biomater 2014;10:2147-58.

[11] Liu H, Wang Y, Wang M, Xiao J, Cheng Y. Fluorinated poly(propylenimine) dendrimers as gene vectors. Biomaterials 2014;35:5407-13.

[12] Liu T, Xue W, Ke B, Xie M-Q, Ma D. Star-shaped cyclodextrin-poly(l-lysine) derivative co-delivering docetaxel and MMP-9 siRNA plasmid in cancer therapy. Biomaterials 2014;35:3865-72.

[13] Jewell CM, Lynn DM. Surface-mediated delivery of DNA: cationic polymers take charge. Curr Opin Colloid Interface Sci 2008;13:395-402.

[14] Farrell LL, Pepin J, Kucharski C, Lin X, Xu Z, Uludag H. A comparison of the effectiveness of cationic polymers poly-L-lysine (PLL) and polyethylenimine (PEI) for non-viral delivery of plasmid DNA to bone marrow stromal cells (BMSC). Eur J Pharm Biopharm 2007;65:388-97.

[15] Snyder SL, Sobocinski PZ. An improved 2,4,6-trinitrobenzenesulfonic acid method for the determination of amines. Anal Biochem 1975;64:284-8.

[16] Gebhart CL, Kabanov AV. Evaluation of polyplexes as gene transfer agents. J Control Release 2001;73:401-16.

[17] Gratton SE, Ropp PA, Pohlhaus PD, Luft JC, Madden VJ, Napier ME, et al. The effect of particle design on cellular internalization pathways. Proc Natl Acad Sci U S A 2008;105:11613-8.

[18] Behr J-P. The proton sponge: a trick to enter cells the viruses did not exploit. CHIMIA Int J Chem 1997;51:34-6.

[19] Akinc A, Thomas M, Klibanov AM, Langer R. Exploring polyethylenimine-mediated DNA transfection and the proton sponge hypothesis. J Gene Med 2005;7:657-63.

[20] Putnam D, Gentry CA, Pack DW, Langer R. Polymer-based gene delivery with low cytotoxicity by a unique balance of side-chain termini. P Natl Acad Sci 2001;98:1200-5.

[21] Godbey WT, Wu KK, Mikos AG. Poly(ethylenimine) and its role in gene delivery. J Control Release 1999;60:149-60. 
[22] Park J, Park J-K, Nam J-P, Kim W-S, Choi C, Kim M-Y, et al. Preparation of pullulan-g-poly(L-lysine) and it's evaluation as a gene carrier. Macromol Res 2012;20:667-72.

[23] Hwa Kim S, Hoon Jeong J, Joe CO, Gwan Park T. Folate receptor mediated intracellular protein delivery using PLL-PEG-FOL conjugate. J Control Release 2005;103:625-34.

[24] Neu M, Fischer D, Kissel T. Recent advances in rational gene transfer vector design based on poly(ethylene imine) and its derivatives. J Gene Med 2005;7:992-1009.

[25] Fischer D, Bieber T, Li Y, Elsasser HP, Kissel T. A novel non-viral vector for DNA delivery based on low molecular weight, branched polyethylenimine: effect of molecular weight on transfection efficiency and cytotoxicity. Pharm Res 1999;16:1273-9.

[26] Godbey WT, Wu KK, Mikos AG. Size matters: molecular weight affects the efficiency of poly(ethylenimine) as a gene delivery vehicle. J Biomed Mater Res 1999;45:268-75.

[27] Morimoto K, Nishikawa M, Kawakami S, Nakano T, Hattori Y, Fumoto S, et al. Molecular weightdependent gene transfection activity of unmodified and galactosylated polyethyleneimine on hepatoma cells and mouse liver. Mol Ther 2003;7:254-61.

[28] Fitzsimmons RE, Uludag H. Specific effects of PEGylation on gene delivery efficacy of polyethylenimine: interplay between PEG substitution and N/P ratio. Acta Biomater 2012;8:3941-55.

[29] Gabrielson NP, Pack DW. Acetylation of polyethylenimine enhances gene delivery via weakened polymer/DNA interactions. Biomacromolecules 2006;7:2427-35.

[30] Teo PY, Yang C, Hedrick JL, Engler AC, Coady DJ, Ghaem-Maghami S, et al. Hydrophobic modification of low molecular weight polyethylenimine for improved gene transfection. Biomaterials 2013;34:7971-9.

[31] Shahidi-Hamedani N, Shier WT, Moghadam Ariaee F, Abnous K, Ramezani M. Targeted gene delivery with noncovalent electrostatic conjugates of sgc-8c aptamer and polyethylenimine. J Gene Med 2013;15:261-9.

[32] Dai J, Zou S, Pei Y, Cheng D, Ai H, Shuai X. Polyethylenimine-grafted copolymer of poly(l-lysine) and poly(ethylene glycol) for gene delivery. Biomaterials 2011;32:1694-705.

[33] Zhang M, Liu M, Xue YN, Huang SW, Zhuo RX. Polyaspartamide-based oligo-ethylenimine brushes with high buffer capacity and low cytotoxicity for highly efficient gene delivery. Bioconjug Chem 2009;20:4406.

[34] Wang CF, Lin YX, Jiang T, He F, Zhuo RX. Polyethylenimine-grafted polycarbonates as biodegradable polycations for gene delivery. Biomaterials 2009;30:4824-32.

[35] Tian H, Lin L, Jiao Z, Guo Z, Chen J, Gao S, et al. Polylysine-modified polyethylenimine inducing tumor apoptosis as an efficient gene carrier. J Control Release 2013;172:410-8.

Figure captions:

- Figure1. Synthesis of alkylcarboxylate PLL-grafted PEI derivatives.

- Figure2. The ethidium bromide exclusion assay

- Figure 3. Buffering capacities of polymers.

- Figure4. Cellular toxicity and transfection efficiency of modified polymers. 